\title{
New trends of landslide disasters after impoundment of the Three Gorges Reservoir, China, and reflections related to landslide prevention
}

\author{
Chao Zhang ${ }^{1, \text { a }}$, Rubin Wang ${ }^{2, b}$ \\ ${ }^{1}$ Research Institute of Geotechnical Engineering, Hohai University, Nanjing 210098, China \\ ${ }^{2}$ Key Laboratory of Ministry of Education for Geomechanics and Embankment Engineering, Hohai \\ University, Nanjing 210098, China \\ a zchohai@foxmail.com; ${ }^{b}$ rbwang_hhu@foxmail.com
}

\begin{abstract}
Keywords: Three Gorges Reservoir; Landslide disaster; Recommendations; Factors causing landslides; New trends

Abstract. Based on typical historic landslide disasters in the Three Gorges Reservoir, in this short communication, the most important factors that are likely to induce landslides in the reservoir region were explored, and the new trends of landslide disasters after impoundment of the reservoir region were comprehensively analyzed. In summary, although most landslide incidents along the banks of the Three Gorges Reservoir Region have been induced by the combined effects of rainfall and changes in water-level after impoundment of the reservoir, people activity of production and livelihood forment and aggravate development of landslide disasters. Finally, the new reflections were proposed for addressing problems that occurred related to landslide prevention and disaster management after reservoir impoundment.
\end{abstract}

\section{Introduction}

The Three Gorges Project, including the reservoir along the Yangtze River, has complex natural and geological conditions. This region is prone to geologically-related disasters caused by the expansive submerged area, the limited capacity of the environment to contain disasters, and frequent storms and floods[1-3]. Therefore, the effects of landslides within the Three Gorges Project reservoir have created a considerable amount of controversy. In particular, after impoundment the water level in the reservoir reached $135 \mathrm{~m}, 156 \mathrm{~m}$, and later $175 \mathrm{~m}$ in 2003, in 2006 and later in 2006; the number of landslides occurring at sites with geological hazards has increased significantly[4]. This occurred because the level of water in the reservoir changed and heavy rains occurred during the flood season, directly affecting the security of people's lives and property.

On June 24, 2015, a massive landslide occurred in the Three Gorges Reservoir on the left bank of Daning River in Wushan County, Chongqing City, and triggered 5-6 $\mathrm{m}$ high swells in the reservoir area, capsizing a large number of ships. This incident once again aroused doubts and concerns among the general public related to landslide disasters induced by the impoundment of the Three Gorges Reservoir as well as the corresponding issues related to environmental and geological conditions in the region. Therefore, managers need to understand how to properly address the new trend in the occurrence of frequent landslides that have occurred after the impoundment of the Three Gorges Reservoir.

\section{Factors Causing Landslides in the Three Gorges Reservoir}

After the normal impoundment of water in the Three Gorges Reservoir, heavy rainfall and changes in the water level within the reservoir during the flood season resulted in frequent landslides.

Liangshuijing Landslide. Since March 10, 2009, flood control efforts caused the water level in the reservoir to decline. The Liangshuijing Landslide deformation was aggravated; cracks on the trailing and side edges of the landslide coalesced, and the cracks on both sides extended to the river. On April 1, 2009, the situation became dangerous at the site of the Liangshuijing Landslide; the cracks in the surrounding landslide material coalesced, and houses on the landslide were severely 
deformed exposing an apparent trend of a whole-body slide. The panorama of the Liangshuijing Landslide and the deformation in the trailing edge of the landslide is shown in Fig.1.
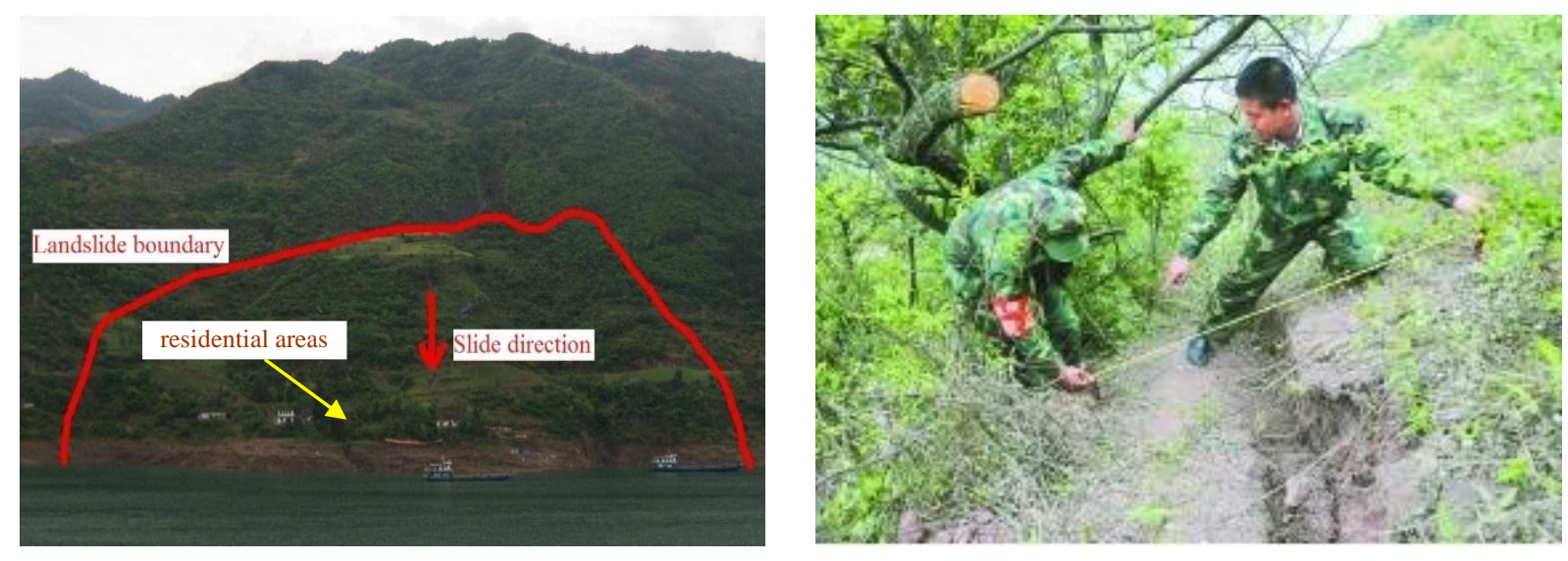

Fig. 1. Panorama of the Liangshuijing Landslide and the deformation in the trailing edge of the landslide.

(Sources: Xihuanet 2009)

The site investigation showed that the Liangshuijing landslide body was between 250-370 m long and 200-370 m wide with a mean thickness of $20 \mathrm{~m}$; the total volume encompassed about 3.6 million $\mathrm{m} 3$. If such a massive landslide body suddenly slides into the reservoir, this will create a serious threat to passing ships, block part of the Yangtze River waterway, and the consequences would be disastrous.

Analysis of factors inducing reservoir landslide hazards. Most landslides after impoundment of the Three Gorges Reservoir have been induced by the combined effects of rainfall and changes in water-level after impoundment of the reservoir. The Hongyanzi and Shanshucao landslides are typical examples of heavy-rain-induced reservoir bank landslides, and the Liangshuijing Landslide is typical example of changes in water-level- induced reservoir bank landslides after impoundment of the reservoir. Therefore, the combined effects of changes in water levels in the reservoir and heavy rains are new factors that may induce disastrous landslides in the reservoir bank after the impoundment of the Three Gorges Reservoir.

Even more important, the Hongyanzi, Shanshucao, and Liangshuijing landslides, the three typical examples, were affected by human factors to various degrees. Therefore, human factors including many unreasonable human engineering activities as well as soil and water loss during the resettlement, relocation and reconstruction processes in the reservoir region are also very important factors that may induce landslides. Landslides are also a major cause of a significant loss of life and property in the reservoir.

\section{Analysis of the new trends of landslide disasters after impoundment of the Three Gorges Reservoir}

Human-Factor-Induced Landslides in the Three Gorges Reservoir Region are the main future trends of the landslide hazards. During the process of urban relocation during the impoundment of the Three Gorges Reservoir, irrational human activities exacerbated the instability of the reservoir banks creating the possibility of landslides as described below.

Stability of bedding planes and cut slopes in the reservoir region. The formation of steep slopes was very common during the relocation of the local population; the new reservoir bank area was originally in a semi-stable state, but with the creation of the reservoir became unstable and subject to slumping. For example, bedding planes and cut slopes have become a landslide-related safety major issue related to the construction of the new settlements for Padang and Wushan counties; the stability of bedding planes and cut slopes in the reservoir region will continue to be a concern in the future. New Wushan County constructed in the Three Gorges Reservoir Region following the relocation after the Hongyanzi Landslide is shown in Fig.2. 

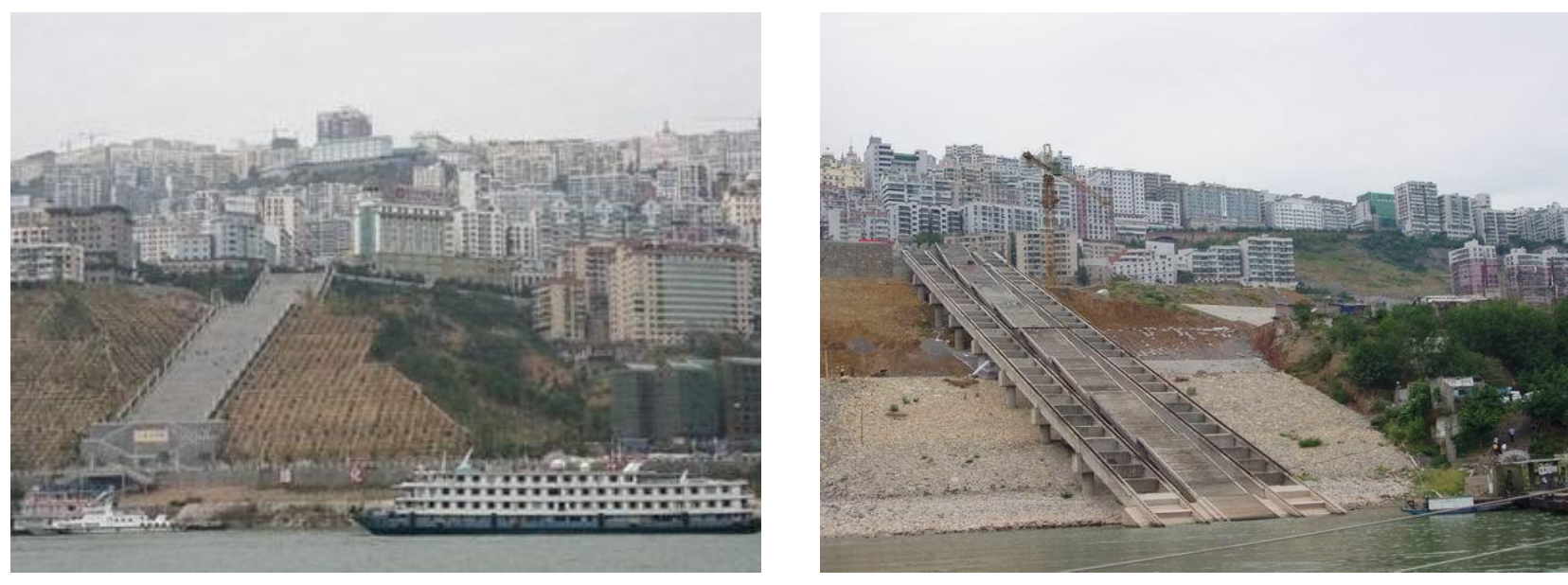

Fig.2. New Wushan County constructed in the Three Gorges Reservoir Region following the relocation after the Hongyanzi Landslide. (Sources: Baidu)

Unstability of reservoir bank induced by high density buildings. In the cities and towns around the reservoir, a large number of high density buildings were constructed to relocate local residents; these buildings increased the load on the land surrounding the reservoir. In some towns, the body of some steep slopes (slope angle greater than $20^{\circ}$ ) has been deformed because of the densely packed high-rise buildings. After impoundment, the water softened the lower part of rock and soil along the river, increasing the likelihood that the upper slope would become compressed and the lower part was saturated with water. Residential buildings constructed on cut slopes in the Three Gorges Reservoir area is shown in Fig.3. As a result, the reservoir bank became unstable in some areas, which has created a major potential threat to the safety of residents in the Three Gorges Reservoir Region.
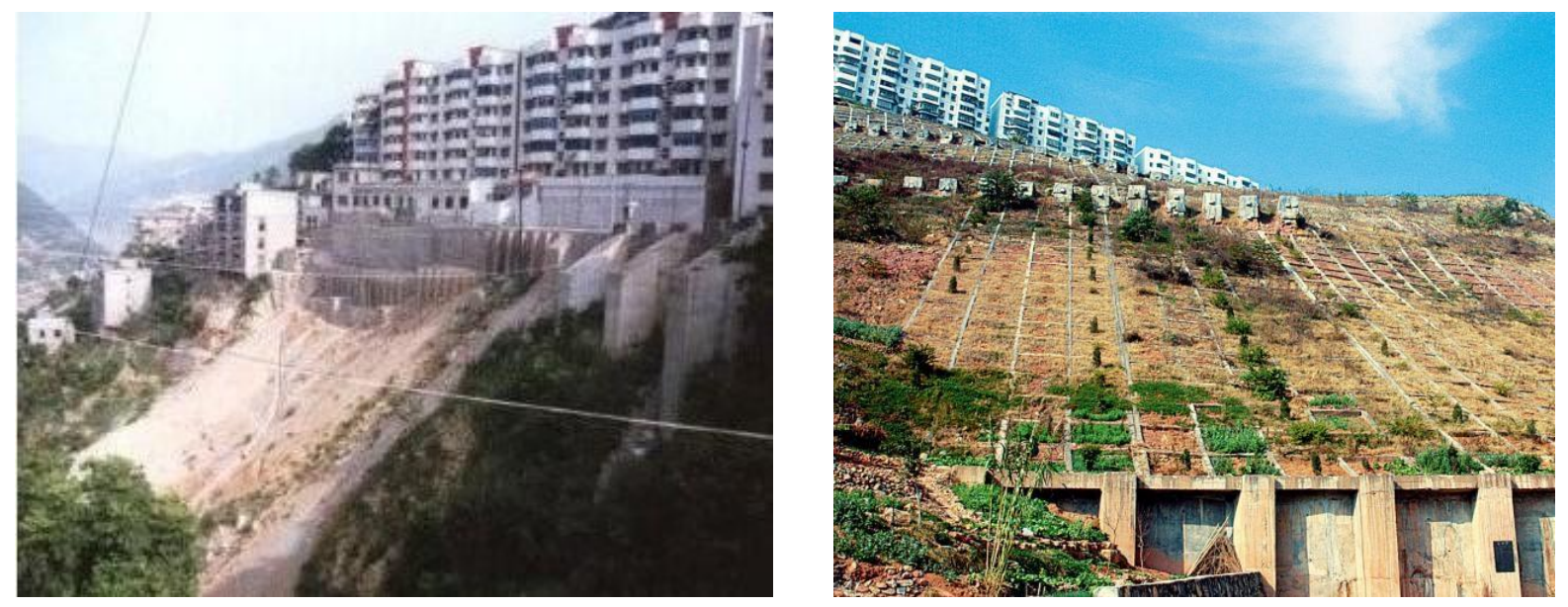

Fig.3. Residential buildings constructed on cut slopes in the Three Gorges Reservoir area. (Sources: Baidu)

Spoil problems during the relocation process in the reservoir region. A large amount of spoil created during the relocation process has not been processed properly in many cities and towns; drainage was not adequately considered during the side slope design, resulting in poor surface drainage, soil erosion, and even the formation of new landslides and debris flows. Currently, Fengjie, Wushan, Badong, Zigui, and Xingshan counties have encountered spoil problems, as is shown in the Fig.4, which can lead to human-caused landslides and mudslides, pose a threat to and pollute the Yangtze River waterway, and destroy the bridges across the ditches. During the urban relocation process, the engineering spoil needed to be treated promptly to prevent the threats created by engineering spoil to the Yangtze River Waterway and the poorly planned new sites recently created for displaced persons 
Lack of overall planning for the relocation of many towns in the reservoir region. The planning for the relocation and construction of many towns in the reservoir region has not been strictly based on the currently topographical and geological conditions, and some new town sites have even been located in the slump, landslide, and debris flow-prone areas; these areas are typically caused by large-scale fill and excavation sites. This seriously affects the stability of the reservoir bank, and leaves some potential risks of geological disasters. For example, the new Badong County was developed under complex geological conditions, with surface fragmentation and steep slopes. Because of the large-scale of cut slopes created along the river, the stability of the bank slope is undermined, and a large number of landslides have occurred, such as the Zaozishu and Huangtupo landslides resulting in significant economic losses, as shown in Fig.5.
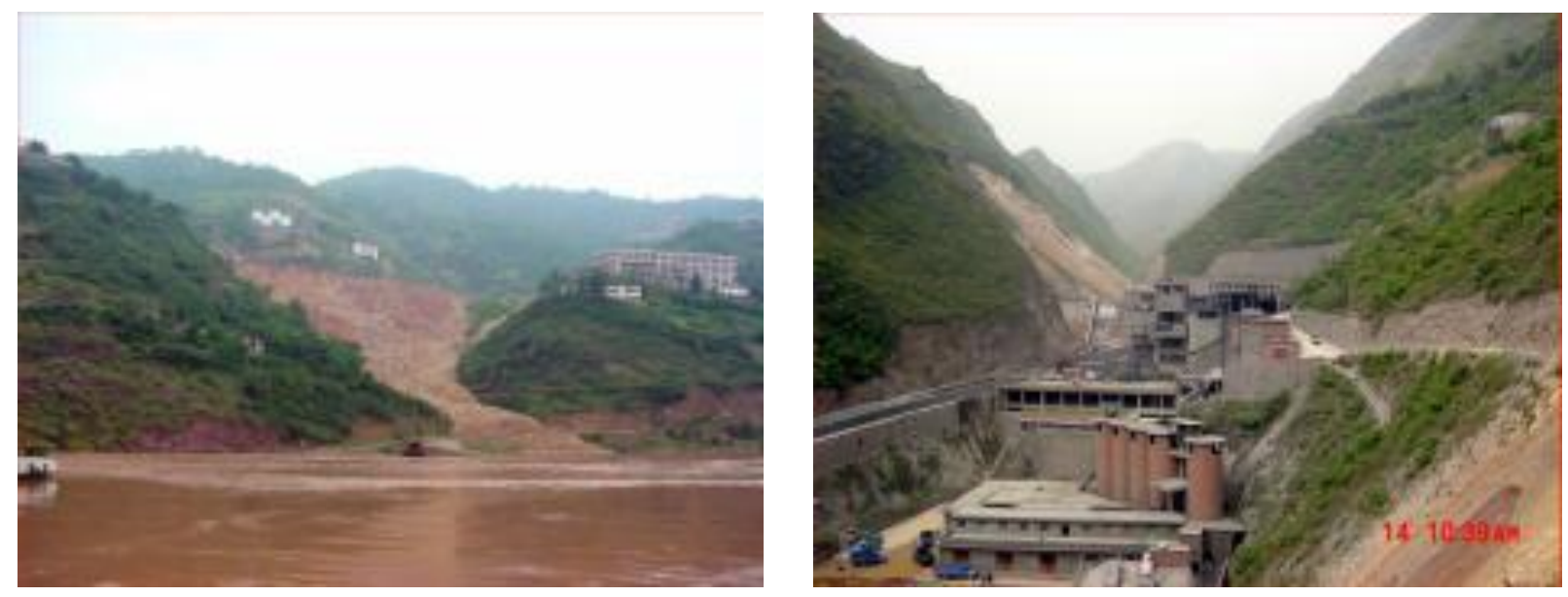

Fig. 4 Threats from spoil left from engineering operations to the Yangtze River Waterway and new residential sites constructed to house displaced persons. (Sources: Baidu)
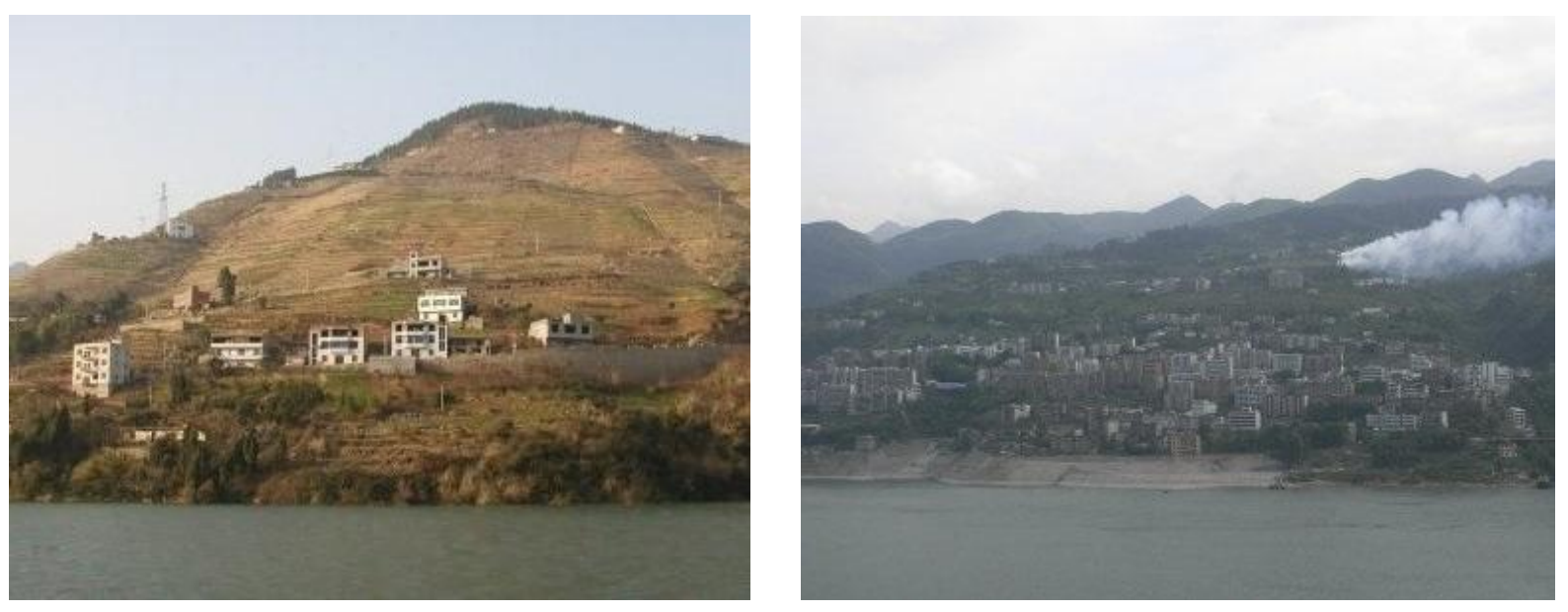

Fig. 5 Zaozishu and Huangtupo landslides in Badong County, Hubei Province, China. (Sources: Baidu)

\section{Reflections related to landslide prevention in the reservoir area}

The implementation of the quality of landslide treatment projects. The quality of landslide treatment projects played a significant role after impoundment of the Three Gorges Reservoir. Currently, many problems remain related to reservoir bank protection and landslide treatment in the Three Gorges Reservoir Region. For example, as is shown in Fig.6 and Fig.7, during the reservoir impoundment and trial operation in 2007, 33 concrete slide piles on the slope of the Shijiapo Landslide in Badong County showed different degrees of deformation[5]. Since the reservoir impoundment in 2006 with the water level reaching $156 \mathrm{~m}$, a slow deformation has been documented in the Majiagou Landslide in Zigui County. A relatively large deformation with a maximum deformation of about $30 \mathrm{~cm}$ occurred in November 2008 after normal reservoir operation, and slide 
piles on the top of the slope showed inclinations toward the outside of the slope with a maximum inclination angle of about $2^{\circ}[5]$.

The above situations indicate that although some bank landslides have been adequately treated, landslide disasters can still occur if appropriate geological surveys are not in place, if the treatment measures are not strictly implemented, and if the engineered structures are not of high quality. Therefore, based on the different geological conditions of reservoir bank landslides, a principle of combining adequate engineering and non-engineering measures is recommended to strengthen the protection of the reservoir bank and to enhance the quality and efficiency of bank landslide treatment and urban protection projects.

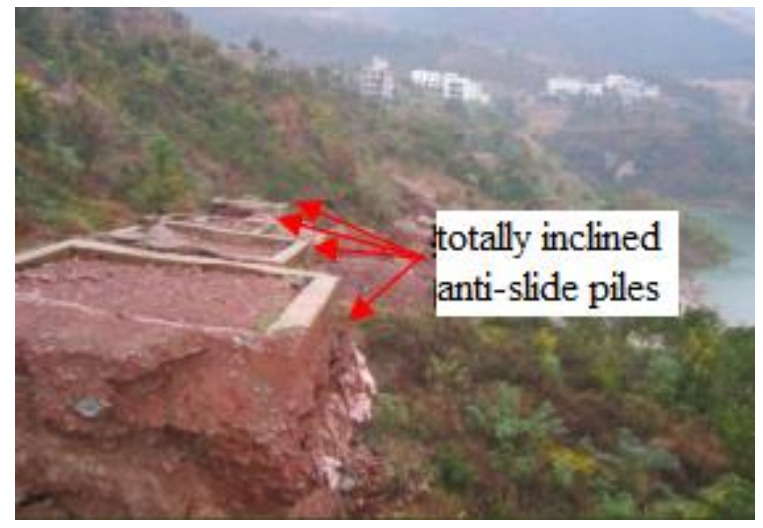

Fig. 6 Large deformation of slide piles on the Shijiapo Landslide in Badong County

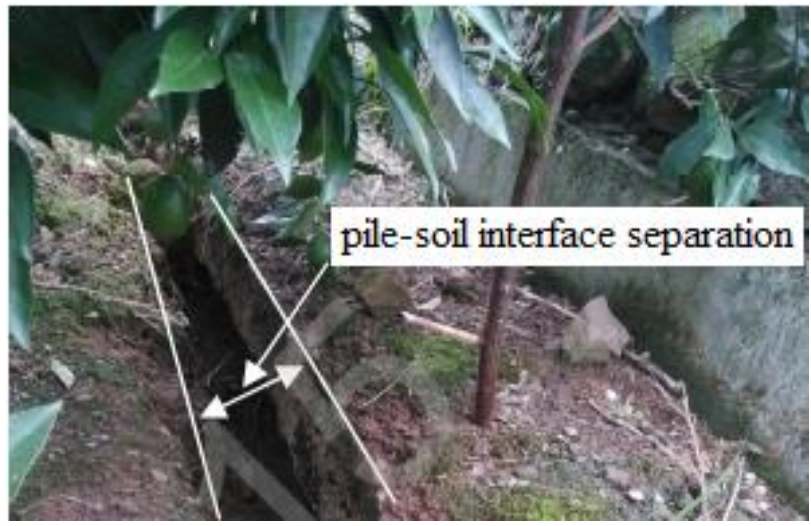

Fig. 7 Large deformation of slide piles on the Majiagou Landslide in Zigui County

The rise of the geological monitoring and early-warning system in the reservoir area. Effective monitoring and early warning of geological disasters is the best way to prevent and mitigate disasters. However, the geological monitoring and early-warning system that was initially established in the Three Gorges Reservoir Region has inadequate coverage. All known important landslides should be included in the monitoring and early-warning system, and further research should be conducted on the technical methods and management operation system that are suitable for larger scale monitoring and early warning activities.

In particular, widespread applications of GPS and other advanced monitoring methods should be promoted, a disaster monitoring and prevention network involving the general public should be further improved, bank slope deformation should be monitored closely in many areas, and slump and other unexpected disasters should be forecasted in advance. In addition, a comprehensive analysis of professional monitoring conclusions should be strengthened, data analysis should integrate factors such as surface and subsurface deformation, changes in groundwater, rainfall, and reservoir water level, and the trend of potential landslide masses should be analyzed and determined.

Rational human activities in the reservoir area. The Three Gorges Reservoir Region is a densely populated area with frequent conflicts between people and land use plans; for example, people often cultivate land on steep slopes. According to statistics (Chen et al., 2005), 34,600 km2 of the area in the reservoir region is susceptible to soil erosion, with an annual total soil erosion of 153 million tons. Therefore, we should conduct reasonable land use planning in the reservoir area, improve the land use patterns, and prevent soil erosion.

As one type of geological disaster, the major landslides in the reservoir area are caused by the slumping of the river bank that is composed of loose soil along the river. Furthermore, many residential houses in the reservoir area have been built in a poorly planned and disorderly fashion and are close to the reservoir bank. This is extremely inappropriate and can artificially exacerbate the occurrence of reservoir landslide disasters. Therefore, the government should conduct more reasonable planning related to reservoir resettlement and urban relocation, and properly solve the issues arising from irrational human activity that has induced landslide disasters in the reservoir area. The government should provide the greatest possible protection for the lives of people and their 
property in the reservoir area; this should be done by ensuring the strengthening of bank slope protection and controlling landslides.

In addition, the relocation of local residents should be done using strengthened theoretical research and engineering design that consider adequate engineering and geological analysis. We also should be focused on resolving the toe-cutting problems of clinal slopes and landslide bodies that frequently occur during urban relocation. In addition, issues related to landslide reinforcement in semi-submerged areas and the use of spoil to backfill gullies should be addressed, as well as the issues related to development and land use.

\section{Conclusions}

The Three Gorges Project is a remarkable grand project, and landslides are a potential type of geological disaster that is an important factor that may plague the normal operation of the reservoir and reservoir related resettlement of the local people. Therefore, the prevention and control of landslide disasters in the reservoir area is very challenging, and a major breakthrough must be made in the theory and practice of landslide disaster management to reveal the new trends in the landslide disasters of the Three Gorges Reservoir Region. In the future, strengthening the study of the patterns of the regional distribution of landslides and " $3 \mathrm{~S}$ " detection technology is needed. A dynamical model of the evolution of three-dimensional space and time of geological disasters should be developed, and the analysis, prediction and evaluation of nonlinear theory should be conducted. Efforts should be focused on important research topics such as the combined effects of rainfall and reservoir water level on the stability of landslides in the reservoir area. In addition, monitoring and early warning systems should be analyzed and an information management system established, and numerical simulation technology should be used to provide a new level of landslide prevention and control of in the Three Gorges Reservoir Region.

\section{Acknowledgements}

This work was financially supported by the National Natural Science Foundation of China (No.51409082), and China Postdoctoral Science Foundation (2013M531264).

\section{References}

[1] F.W. Wang, Y.M. Zhang, Z.T. Huo, T. Matsumoto, B.L. Huang: Landslides Vol.1 (2004), p. 157.

[2] Y.P. Yin, H.D. Wang, Y.L. Gao, X.C. Li : Landslides Vol.7 (2010), p. 339.

[3] M. Xia, G.M. Ren, X.L. Ma: Nat Hazards Vol.68 (2013), p.467.

[4] T. Peng, G. Xu, D.Q. Xia: China Development, Vol. 4 (2004), p. 8. (In Chinese)

[5] Z.H. Zhang, Q.H. Jiang, C.B. Zhou, X.T. Liu: Geophys J Int Vol.198(2014), p1034.

[6] J. Chen, Z.F. Yang, X. Li: Chinese Journal of Rock Mechanics and Engineering Vol.24(2005): p.3052-3056. (In Chinese) 